\section{Budget instructions}

\section{US science agencies may need to prove they are solving national problems. David Goldston explains.}

ast month, the administration of US President Barack Obama released the first document that hints at how it intends to shape the science and technology budget for fiscal year 2011. If the administration rigorously applies the principles in the document, federal science agencies may need to alter their focus and procedures. For better or for worse, that is making universities' lobbyists jittery.

Although fiscal year 2011 does not begin until 1 October 2010, and the president's proposed budget will not be released until February, drafting has already begun, and this will be the first spending plan that bears the full imprint of the Obama administration. (Fiscal 2009 began before Obama took office, and the 2010 budget was pulled together on a highly abbreviated schedule before all the key administration officials were in place.) So this is the first time that the president's science adviser, John Holdren, and budget director, Peter Orszag, have gone through the annual exercise of jointly issuing a memorandum to guide the agencies as they prepare their budgets for White House review.

What is striking about the 4 August memo is its emphasis on tightly linking research programmes to solving what are pointedly labelled as "practical challenges", its focus on evaluating programme outcomes with data that would be made publicly available, and its call for shifting money away from "lower priority" areas. The document is also notable for what it omits: the term 'basic research' is never used, no mention is made of the president's commitment to double the budgets of several science agencies and no new cross-agency programmes are proposed.

All this, together with the memo's vague directive that agencies should work to improve "the productivity of our research institutions, including our research universities", has been greeted with consternation in universities' Washington offices, and university groups are discussing how to respond. But the memo may win favour with advocates of technology policy, who have complained that the administration is too focused on science and not enough on how to promote innovation in the economy. The document should also bring smiles to academic science-policy experts, who for years have argued that the science budget should be designed more to address specific

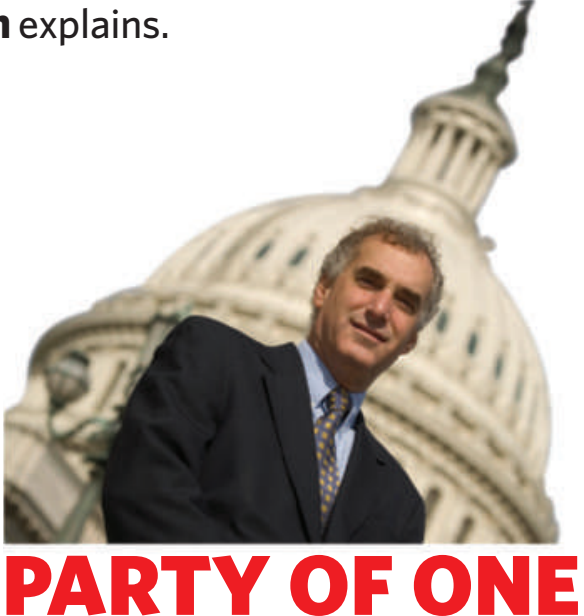

national needs and less to satisfy the interests of researchers and agencies.

The key question, of course, is how the memo will be implemented. Take, for example, biomedical research. Holdren and Orszag define the "practical challenge" for that field as "applying biomedical science and information technology to help Americans live longer, healthier lives while reducing health care costs". Does that mean that the National Institutes of Health will have to make a case that its proposed research will lead in some definable and measurable way to lower health-care costs? Or will it be able to make a generic claim, as it has in the past, that research can reduce health expenses? The memo seems to say that mere assertions will no longer be sufficient, arguing that "agencies have a responsibility to explain how Federal science and technology investments contribute to ... improved health outcomes" and to prove it with data.

Pushing agencies to build their budgets around specific and measurable outcomes that would benefit the public could have a salutary effect - if it doesn't put programmes in a straitjacket. The memo does instruct agencies to "support long-term, visionary thinkers proposing high-risk, high-payoff research" and requires agencies to come up with metrics to determine whether such research is being supported. But an emphasis on specific outcomes, which include "job creation", can push agencies away from riskier projects.

Moreover, no previous administration has been particularly good at figuring out how to evaluate science programmes, especially those that involve fundamental research. The administration of George W. Bush created something called the Program Assessment Rating Tool to review all programmes, but even Bush officials were cautious in applying it to basic science. In any event, the tool never gained widespread acceptance within the government, and agencies complained that budget decisions often did not take account of the ratings.

A lot of intellectual work will be needed to develop appropriate metrics - some of that is ongoing under the National Science Foundation's Science of Science and Innovation Policy effort - and to limit the burden of gathering data. And a crucial task will always be to decide how quickly an outcome should become evident — inherently an art as much as a science, and a political art at that.

The Obama administration is trying to come up with measures to determine the impact of the American Recovery and Reinvestment Act, which promised short-term job growth, including through science spending. Some university officials were rightly uneasy about the precedent of evaluating science programmes on that basis, but the memo explicitly cites the Recovery Act as a positive precedent for "transparency" and lists job creation as a goal for science and technology programmes, although it does not specify a time period (see Nature 458,$563 ; 2009$ ).

The memo also stresses the link between research and practical results by directing agencies to "empower their scientists to have ongoing contact with people who know what's involved in making and using things", including "cost and competitive factors". The hint of contempt for the ivory tower in the phrasing is surprising, but the idea makes sense for some programmes, especially those that are supposed to yield new energy technologies another of the memo's "practical challenges". But here, too, the trick will be to get the balance right: an over-emphasis on working with industry or entrepreneurs may limit the scope of research, play into the hands of incumbent market players or create problematic conflicts of interest, especially in the biomedical arena.

The need for balance, however, is not a reason to stick to the status quo. And given the inertia in the funding system, the research enterprise is unlikely to lurch into perilous territory overnight. The administration seems to be sidling into challenging science agencies to think more rigorously about contributing to explicit national goals. But figuring out how to do that, especially if funding is tight, will be a years-long experiment.

David Goldston (partyofonecolumn@gmail. com) is the director of government affairs at the Natural Resources Defense Council in Washington DC. Views expressed are his own. 